05

\title{
Влияние постоянных магнитных полей на динамику расплавленных зон в поле структурной неоднородности кремния
}

\author{
() А.А. Скворцов, Д.Е. Пшонкин, М.В. Корячко, М.Р. Рыбакова
}

Московский политехнический университет, Москва, Россия

E-mail: SkvortsovAA2009@yandex.ru

Поступило в Редакцию 28 февраля 2018 г.

Рассматривается влияние постоянных магнитных полей на формирование и динамику расплавленных включений $\mathrm{Al}-\mathrm{Si}$ в кремнии в поле структурной неоднородности кристалла (градиента концентрации дислокаций). Экспериментально зафиксированы скорости миграции жидких включений в кристаллах в условиях преобладания механизмов плавления-кристаллизации на межфазных границах расплава с матрицей до и после магнитной экспозиции. Обнаружено, что предварительная экспозиция дислокационных образцов кремния в постоянном магнитном поле приводит к увеличению скорости перемещения расплавленных зон в поле градиента концентрации.

DOI: 10.21883/PJTF.2018.11.46202.17269

Известно, что миграция вторых фаз в различных твердых телах может осуществляться в виде расплавленных включений [1]. В полупроводниковых кристаллах подобные объекты могут образовываться при росте сильнолегированных кристаллов [2], зонной плавке градиентом температуры [3], легировании [4], а также в условиях тепловой деградации структур на межфазных границах металл-полупроводник при высоких электрических нагрузках [5-7]. Известно также [1,8], что динамика расплавленных зон в кристаллах возможна не только в присутствии электрических и тепловых полей $[1,2]$, но и в условиях неоднородного распределения структурных дефектов кристалла (вакансии, дислокации и т.д.).

Следует также отметить, что в полупроводниках (в частности, в монокристаллическом кремнии) наряду с миграцией расплавленных зон в поле градиента концентрации дислокаций [9] известны явления, связанные с влиянием постоянных магнитных полей на физико-механические 
свойства (так называемые магнитопластические эффекты). В частности, в монокристаллическом кремнии было обнаружено заметное влияние предварительной экспозиции образцов в постоянном магнитном поле на состояние подсистемы структурных дефектов (дислокации и точечные дефекты, в том числе атомы легирующей примеси). Это проявляется в магнитостимулированном увеличении подвижности дислокаций [10], диффузии примеси [11], скорости окисления поверхности $\mathrm{Si}$ [12] и т.д. Причина наблюдаемых изменений связывается со спин-зависимой релаксацией комплексов на основе легирующей примеси [13]. От атомарной структуры образовавшихся в результате релаксации комплексов сильно зависит эффективность их взаимодействия с движущимся дислокационным сегментом [14].

Поэтому цель настоящей работы состоит в выявлении влияния постоянных магнитных полей (МП) на динамику расплавленных зон типа металл-полупроводник в монокристаллическом кремнии в присутствии поля градиента плотности дислокаций.

Известно [1,4], что макроскопическое включение в кристалле может перемещаться как целое либо в поле градиента химического потенциала, поддерживаемого извне, либо под влиянием сил, внутренних по отношению к кристаллу. Это может происходить и в поле структурной неоднородности, в том числе дислокационной $[8,9]$.

Пусть макроскопическое включение расположено в матрице вдоль неоднородного распределения дислокаций $[8,9]$. Пусть также на противоположных межфазных границах включения размером ${ }^{1} l$ плотность дислокаций $N_{d}$ различается на величину $\Delta N_{d}=\left(d N_{d} / d x\right) l$ и $l>>N_{d}^{-1 / 2}$. Рассмотрим также ситуацию, когда диффузионная подвижность атомов матрицы в твердой фазе мала (что и реализуется в монокристаллах кремния), а атомы матрицы растворимы в расплаве. При этом через объем включения и будет реализована диффузия вещества $[1,8,9]$.

При наличии градиента концентрации дислокаций движущей силой процесса миграции является изменение химического потенциала на межфазных границах $\Delta \mu_{k}=\varepsilon \omega_{k}\left(\partial N_{d} / \partial x\right) l$ (здесь и далее $\varepsilon-$ энергия дислокации единичной длины, $\omega_{k}$ - атомный объем в твердой фазе). Наличие скачка химического потенциала и определяет динамику растворения вещества матрицы на „лобовой“ и осаждения на „тыльной“

\footnotetext{
${ }^{1}$ Под размером включения будем понимать наибольший размер зоны неоднородного распределения дислокаций. Например, для сферического включения радиуса $R$ наибольший размер $l=2 R$.
} 
поверхности включения и, таким образом, смещения включения как целого с некоторой скоростью $w$.

В работе [8] была получена размерная зависимость скорости миграции $w(l)$ расплавленной зоны

$$
w=\frac{\bar{\beta} c D_{i}}{c D_{i}+\bar{\beta} \omega_{i} k T l}\left(\varepsilon \omega_{k} \frac{\partial N_{d}}{\partial x} l-\Delta \mu^{*}\right),
$$

где $\Delta \mu^{*}=\Delta \mu_{p}^{*}+\Delta \mu_{0}^{*} ; \Delta \mu_{p}^{*}, \Delta \mu_{0}^{*}-$ скачки химического потенциала на растворяющейся и растущей поверхностях включения; $\bar{\beta}=\frac{\beta_{0} \beta_{p}}{\beta_{0}+\beta_{p}}$; $\beta_{0}, \beta_{p}$ - нормированные на $k T$ удельные потоки растворения и кристаллизации; $D_{i}, \omega_{i}, c-$ коэффициент диффузии, атомный объем и концентрация в объеме включения. Из (1) следует условие движения включения $\varepsilon \omega_{k} \frac{\partial N_{d}}{\partial x} l>\frac{\Delta \mu^{*}}{\varepsilon \omega_{k}}$ как целого. Оценки, проведенные в $[8,9]$, показывают, что смещаться будут только те включения, у которых плотность дислокаций на лобовой и тыльной поверхностях различается на величину $\Delta N_{d} \sim 10^{6}-10^{8} \mathrm{~cm}^{-2}$. Кроме того, известно $[15,16]$, что на начальных стадиях контактного плавления появлению расплава предшествуют диффузионные процессы вблизи межфазных границ. Диффузия вещества в области контакта способствует образованию областей твердых растворов с концентрациями, близкими к пределу растворения примеси. Пересыщение этих областей связывают с дефектной подсистемой, в том числе с дислокациями, плотность которых в нашем случае весьма высока. Линейные дефекты служат диффузионными каналами, обеспечивающими интенсивный перенос вещества и насыщение этих каналов до концентраций, соответствующих стехиометрическому составу эвтектики. При последующем нагреве такие микрообласти переходят в жидкую фазу, разрастаясь с течением времени в сплошную эвтектическую зону $[15,16]$.

Таким образом, состояние линейных дефектов (подвижность, число точек закрепления на единицу длины, наличие примесных атмосфер и т. д.) может существенно влиять динамику расплавленных зон. Поэтому изменение состояния дислокационной структуры (например, с помощью постоянных магнитных полей) может отразиться на процессе формирования и миграции расплавленных зон в описанных выше условиях.

Экспериментальное изучение влияния постоянных магнитных полей на динамику расплавленных зон в поле структурной неоднородности

7* Письма в ЖТФ, 2018, том 44, вып. 11 
осуществлялось на кристаллах кремния $n$-типа $(\rho=1 \Omega \cdot \mathrm{cm})$ размером $3 \times 3 \times 15 \mathrm{~mm}$. Как и ранее [9], градиент концентрации дислокаций создавался изгибом образцов при температуре $1323 \mathrm{~K}$. Полученные образцы разрезались в месте максимального градиента, после чего между торцами образцов зажималась тонкая пленка алюминия и производился отжиг в инертной атмосфере в диапазоне температур $T=800-1100^{\circ} \mathrm{C}$. Методика проведения опытов детально изложена в $[9,17]$. Единственным отличием была предварительная экспозиция образцов перед отжигом в инертной атмосфере в постоянном магнитном поле, которое создавалось между полюсами постоянных магнитов с индукцией в зазоре $B=0.7 \mathrm{~T}$. При экспонировании линии индукции магнитного поля были перпендикулярны длинной грани образца. Время экспонирования варьировалось от 5 до $120 \mathrm{~min}$. Исследования показали, что основные изменения происходят в первые $10 \mathrm{~min}$ экспонирования в МП. Далее наблюдаемые изменения практически не зависели от времени экспонирования. Поэтому время выдержки образцов в магнитном поле составляло $30 \mathrm{~min}$, а само экспонирование всегда проходило при комнатной температуре перед непосредственным отжигом образцов с введенными дислокациями.

Как и в предыдущих работах $[9,15]$, возникновение расплавленных зон в объеме матрицы при изотермическом отжиге при температурах $1123-1273 \mathrm{~K}$ связано с процессами контактного плавления металлической пленки алюминия с монокристаллом $\mathrm{Si}$ на границе раздела металл-полупроводник (температура плавления эвтектики $\mathrm{Al}-\mathrm{Si}$ coставляет $850 \mathrm{~K})$.

Размер и глубина проникновения включений в матрицу от границы определялись при последовательной шлифовке слоев через каждые $5-10 \mu \mathrm{m}$ с последующей идентификацией включений при помощи оптического микроскопа [9]. Размер включений после кристаллизации находился в диапазоне $20-100 \mu \mathrm{m}$ (рис. 1).

Типичные результаты исследований приведены на рис. 2. Нетрудно видеть, что, как и ранее, размерные зависимости скорости движения включений, зарегистрированные при температурах 1123 и $1173 \mathrm{~K}$, носят линейный характер. Это подтверждает кинетический режим движения включений, т.е. движение расплавленных зон в поле градиента концентрации дислокаций определяется процессами плавлениякристаллизации на межфазных границах расплав-кристалл.

Письма в ЖТФ, 2018, том 44, вып. 11 


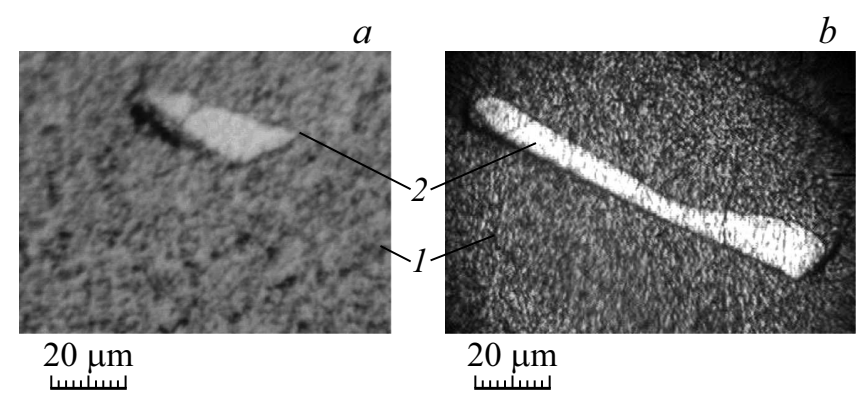

Рис. 1. Фотографии закристаллизованного включения $\mathrm{Al}-\mathrm{Si}$ после миграции в образце, подвергнутом предварительной экспозиции в постоянном магнитном поле при $B=0.7$ Т в течение $30 \mathrm{~min}$ при комнатной температуре $(a)$, и образцесвидетеле без магнитной экспозиции $(b) .1$ - поверхность кремния, 2 закристаллизованное включение.

В этом случае размерная зависимость скорости миграции имеет вид $[9,15]$

$$
w=\bar{\beta} \omega_{k}\left(\varepsilon \omega_{k} \frac{\partial N_{d}}{\partial x} l-\Delta \mu^{*}\right) .
$$

Обращает на себя внимание то, что экспозиция дислокационных образцов кремния в постоянном МП перед отжигом приводит к изменению размерной зависимости скорости $w$ (рис. 2). Увеличение угла наклона может происходить в результате изменения $\bar{\beta}$ и $\frac{\partial N_{d}}{\partial x}$ после экспонирования кристаллов в МП. Полученные результаты согласуются с известными ранее данными по магнитопластическим эффектам в кремнии [10-12].

Более того, было обнаружено, что наиболее сильное влияние предварительной экспозиции в МП проявляется при отжиге кристаллов при температуре $T=1123 \mathrm{~K}$. Увеличение температуры вплоть до $1200 \mathrm{~K}$ приводит к исчезновению магнитостимулированных изменений. Наблюдаемый температурный порог гашения эффекта согласуется с результатами, полученными ранее при изучении магнитостимулированной диффузии в монокристаллах кремния [11], и связывается нами с распадом магниточувствительных центров, оказывающих сильное влияние на дислокационную динамику в полупроводнике. Обращает на себя

Письма в ЖТФ, 2018, том 44, вып. 11 


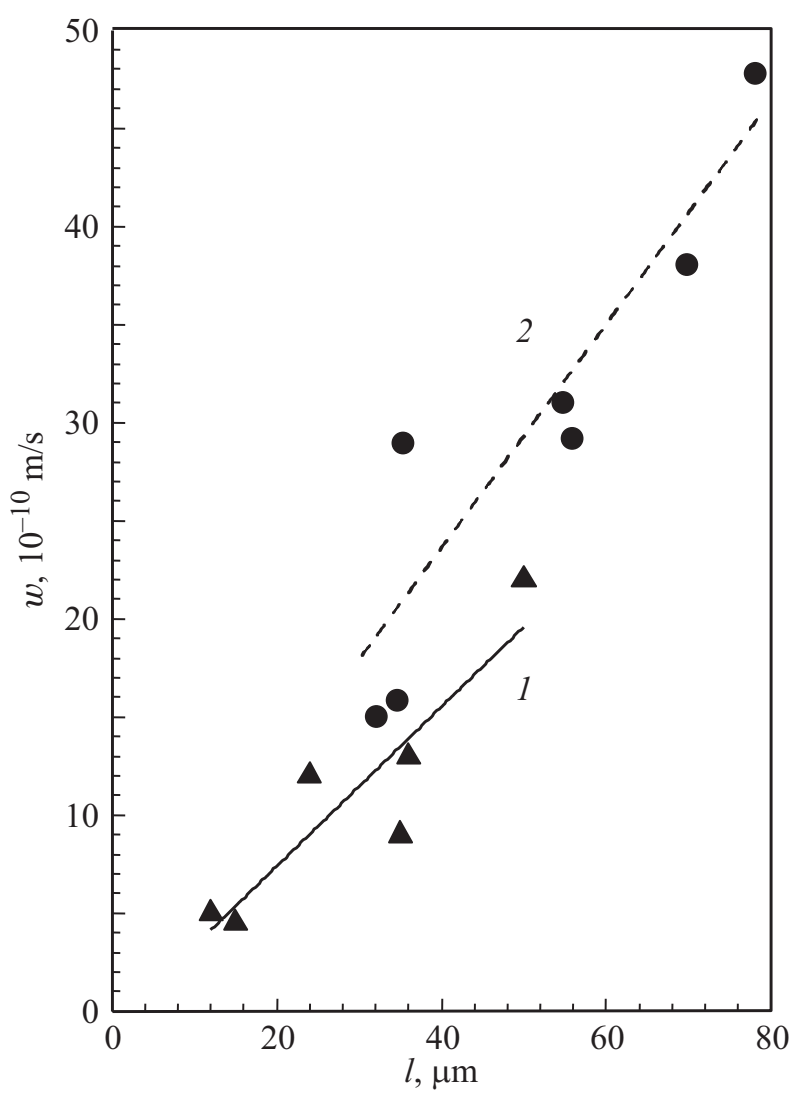

Рис. 2. Размерная зависимость скорости движения включений при температуре изотермического отжига кристаллов кремния $T=1123 \mathrm{~K} .1$ - образцы без экспозиции в магнитном поле, 2 - образцы с предварительной экспозицией в постоянном магнитном поле $B=0.7 \mathrm{~T}$ в течение $30 \mathrm{~min}$ при комнатной температуре.

внимание также размер $l$ движущихся включений: в экспонированных в МП образцах он заметно выше (рис. 2).

Таким образом, в работе рассмотрено влияние предварительной экспозиции образцов Si в постоянном МП на процессы миграции рас-

Письма в ЖТФ, 2018, том 44, вып. 11 
плавленных включений $\mathrm{Al}-\mathrm{Si}$ в монокристаллах кремния при наличии в нем дислокационной неоднородности. Обнаружено, что возникающие расплавленные зоны движутся в поле градиента концентрации дислокаций в область с большей концентрацией, а лимитирующей стадией миграции зон являются процессы плавления-кристаллизации на межфазных границах расплава с матрицей. Экспериментально зафиксировано влияние предварительной экспозиции дислокационных образцов $\mathrm{Si}$ в постоянном магнитном поле на размерную зависимость скорости миграции, а также на размер мигрирующей зоны.

Работа выполнена в рамках проекта Министерства образования и науки РФ № 9.8392.2017/8.9.

\section{Список литературы}

[1] Гегузин Я.Е., Кривоглаз М.А. Движение макроскопических включений в твердых телах. М.: Металлургия, 1971. $344 \mathrm{c}$.

[2] Abe T., Takahashi T., Shirai K. // J. Cryst. Growth. 2017. V. 459. P. 87-94.

[3] Грабов В.М., Комаров В.А., Каблукова Н.С., Демидов Е.В., Крушельницкий А.Н. // Письма в ЖТФ. 2015. Т. 41. В. 1. С. 20-27.

[4] Рейви К. Дефекты и примеси в полупроводниковом кремнии. М.: Мир, 1984. $475 \mathrm{c}$

[5] Demireva D., Ziffudin L., Barbova M. // Semicond. Sci. Technol. 1998. V. 13. Iss. 11. P. 1290-1293.

[6] Skvortsov A.A., Zuev S.M., Koryachko M.V., Glinskiy V.V. // Microelectron. Int. 2016. V. 33. Iss. 2. P. 102-106.

[7] Сквориов А.А., Каленков С.Г., Корячко М.В. // Письма в ЖТФ. 2014. Т. 40. B. 18 . C. $24-32$.

[8] Дзюба А.С. // ФТТ. 1977. Т. 19. В. 1. С. 78-82.

[9] Скворцов А.А., Зуев С.М., Корячко М.В., Волочинов Е.Б. // Письма в ЖТФ. 2017. T. 43. B. 15. C. 42-48.

[10] Макара В.А., Стебленко Л.П., Плющай И.В., Курилюк А.Н., Калиниченко Д.В., Крит А.Н., Науменко С.Н. // ФТТ. 2014. Т. 56. В. 8. С. 1531-1537.

[11] Сквориов А.А., Каризин А.В. // ЖЭТФ. 2012. Т. 141. В. 1. С. 96-100.

[12] Коплак О.В., Дмитриев А.И., Моргунов Р.Б. // ФТТ. 2014. Т. 56. В. 7. C. $1391-1396$.

[13] Осипьян Ю.А., Моргунов Р.Б., Баскаков А.А., Орлов А.М., Скворцов А.А., Инкина Е.Н., Танимото Й. // Письма в ЖЭТФ. 2004. Т. 79. В. 3. С. 158-162.

Письма в ЖТФ, 2018, том 44, вып. 11 
[14] Моргунов Р.Б. // УФН. 2004. Т. 174. № 2. С. 131-157.

[15] Ахкубеков А.А., Орквасов T.A., Созаев В.А. Контактное плавление металлов и наноструктур на их основе. М.: Физматлит, 2008. $152 \mathrm{c}$.

[16] Хайруллаев М.P. // Расплавы. 2009. № 2. С. 68-74.

[17] Skvortsov A.A., Khripach N.A., Zaletov D.V., Pshonkin D.E. // Res. J. Pharm. Biol. Chem. Sci. 2016. V. 7. N 6. P. 998-1003. 